\title{
What can Phase I clinical trials tell us about quality of life? A pilot study (MC0115)
}

\author{
Pamela J Atherton ${ }^{1 *}$, Daniel W Szydlo ${ }^{1}$, Charles Erlichman ${ }^{2}$ and Jeff A Sloan ${ }^{1}$ \\ ${ }^{1}$ Department of Health Sciences Research, Division of Biomedical Statistics and Informatics, Mayo Clinic, USA \\ ${ }^{2}$ Department of Oncology, Mayo Clinic, USA
}

\begin{abstract}
Background: Psychological aspects of patient well-being are not typically included in Phase I clinical trials. We sought to investigate patients' quality of life (QOL) experience, and determine relationships between QOL deficits, treatment outcomes and adverse events.

Methods: Patients completed the Linear Analogue Self Assessment (LASA), Control Preferences Scale (CPS), and Trial Satisfaction (TS) survey. The primary endpoint was change in QOL during cycle 1. Exploratory analyses were conducted utilizing Student's t-test, Wilcoxon, and correlation methodologies.

Results: 23 evaluable patients from 12 trials had an average drop of 0.4 points in overall QOL (effect size (ES) 0.36, p=0.08). Decreases were seen in Physical WellBeing (0.7 points; ES 0.41, p=0.04), Emotional Well-Being (0.6 points, ES 0.46, p=0.04), and Mood (0.9 points, ES 0.50, p=0.03). Four patients experienced a clinically meaningful QOL deficiency (decrease of 2+ points). QOL with AE grade correlations were weak, the highest being for Emotional WB and Hopefulness $(\mathrm{r}=-0.41, \mathrm{r}=-0.35)$. Patients reported trial satisfaction but did not feel trial participation improved QOL.
\end{abstract}

Conclusions: Despite being satisfied with trial experience, significant deficits occurred in QOL subcomponents. It seems advisable to include QOL assessments to identify areas of focus for the alleviation of physical and psychosocial health related QOL.

Abbreviations: QOL: Quality of life, AE: Adverse event, WB: Wellbeing, CPS: Control preferences scale, LASA: Linear analogue self assessment, TS: Trial satisfaction, CTC: Common toxicity criteria

\section{Background}

Quality of Life (QOL) of Phase I oncology clinical trial patients is of interest as the goals of clinicians (defining the maximum tolerated treatment dose and exploring the adverse event (AE) profile) are not necessarily the goals of the patient (finding a cure) [1-6]. Numerous meta-analyses have shown tumor response rates are low on these trials (below 18\%); thus, rather than curative, the Phase I experience is more likely that of symptom exacerbation and treatment-related toxicity [711]. The potential patient disappointment could create QOL deficits. Studies in palliative care and hospice settings, in particular, have indicated the lack of alignment between expectations and outcomes can lead to detriments in psychosocial well-being (WB) and QOL [12-17]. They also indicate that addressing the detriments can provide psychological benefit.

This prospective, exploratory, hypothesis-generating study was designed to assess QOL in Phase I oncology patients enrolled at the Mayo Clinic. The primary hypothesis was to characterize changes in overall QOL during the first cycle of treatment. Secondary hypotheses included describing clinician-rated AEs compared to QOL deficits in all domains, as one or the other may not be sufficiently sensitive to identify patient symptoms. It was also hoped to confirm treatment decision making, hopefulness and perceived potential benefit are important for participation and success.

\section{Methods}

\section{Patient eligibility}

Potential participants in this companion trial were those enrolled on any existing Phase I clinical treatment trial at the Mayo Clinic, without limitation, between September 2002 and March 2007. Clinician and study coordinator discretion determined whether a patient was asked to participate. Eligible patients provided informed consent, were at least 18 years of age, had either advanced solid or hematologic cancers, and had the ability to complete questionnaires. Patients were ineligible if a primary clinician determined the patient had cognitive impairment. This study was approved by the Mayo Clinic Institutional Review Board (\#183-02).

\section{Data collection}

Patients were asked to complete 3 QOL assessments.

1. The Control Preferences Scale (CPS), completed at baseline, consists of two questions measuring patient current and preferred input in the treatment decision-making process. Answers indicated active, collaborative or passive roles. The tool is related to satisfaction with care and patient survival [18].

Correspondence to: Pamela Atherton, Department of Health Sciences Research, Division of Biomedical Statistics and Informatics, Mayo Clinic, 200 1st Street SW, Harwick 836, Rochester, MN 55905, USA, Tel: 507-284-0660; Fax: 507-2662477; E-mail: atherton@mayo.edu

Key words: quality of life, phase I, satisfaction, control preferences, clinical trial

Received: March 06, 2015; Accepted: April 14, 2015; Published: April 17, 2015 
2. Linear Analogue Self Assessment (LASA) measures were completed at baseline and end of cycle 1 . Thirteen individually scored questions measured overall QOL and QOL subdomains (Table 3). These items have been validated at the Mayo Clinic for use in cancer patients [14].

3. The Trial Satisfaction (TS) survey was completed at the end of cycle 1 . The 4 questions assess the degree of patient satisfaction experienced by participating in a trial. These items were adapted from a similar study on patient expectations of clinical trials [3].

Previous research has shown that single item questions are as reliable and valid as their multiple item counterparts [19], thus to avoid undue burden, these were chosen for this study.

\section{Statistical methods}

LASA and TS items were measured on a scale from 0-10, where 10 indicated best QOL. Cycle 1 QOL changes from baseline were calculated. Negative changes denote decreases in QOL. Thus, for clarification, a decrease in pain severity or pain frequency indicates worsening symptoms. Patients were categorized according to a clinically significant decrease in overall QOL (2+ point decrease) [20].

The primary hypothesis was tested using a Student's t-test on the primary endpoint; change from baseline during cycle 1 in LASA overall QOL. Analyses of the secondary QOL endpoints were conducted similarly. Effect sizes, as an indication of clinical meaning, were computed as mean change divided by standard deviation. Sizes of 0.2 , 0.5 , and 0.8 were interpreted as small, medium and large [21].

The National Cancer Institute Common Toxicity Criteria (CTC) $\mathrm{AE}$ rating, CPS measured decision making preferences and TS measured trial satisfaction were compared to each other and LASA outcomes using the Student's t-test, Wilcoxon, Chi-Square and correlation methodologies, as appropriate.

\section{Results}

\section{Patient population}

This study, designed with a projected 300 patients, was closed due to poor accrual after enrolling 30 patients. Seven were not evaluable due to not completing assessments. Eligible $(\mathrm{N}=23)$ patients were accrued from 12 trials having cycle lengths of 21 or 28 days (Table 1). Patients

Table 1. Participating trials.

\begin{tabular}{|c|c|c|c|}
\hline Study & $\begin{array}{c}\text { Patients } \\
\text { in this Trial } \\
\text { (MC0115) }\end{array}$ & $\begin{array}{c}\text { Patients } \\
\text { with endpoint data in this Trial } \\
\text { (MC0115) }\end{array}$ & Reference \\
\hline 1 & 2 & 2 & {$[25]$} \\
\hline 2 & 1 & 1 & {$[26]$} \\
\hline 3 & 5 & 3 & {$[27]$} \\
\hline 4 & 3 & 3 & {$[28]$} \\
\hline 5 & 4 & 2 & {$[29]$} \\
\hline 6 & 2 & 2 & {$[30]$} \\
\hline 7 & 3 & 3 & {$[31]$} \\
\hline 8 & 5 & 3 & {$[33]$} \\
\hline 9 & 2 & 1 & {$[34]$} \\
\hline 10 & 1 & 1 & {$[36]$} \\
\hline 11 & 1 & 1 & \\
\hline 12 & 1 & 1 & \\
\hline
\end{tabular}

*Patients who participated in this trial participated in one of the parent trials listed in this table. The reference for each parent trial is included if available.
Table 2. Baseline patient characteristics.

\begin{tabular}{|c|c|}
\hline & Evaluable Patients $(\mathrm{N}=\mathbf{2 3})$ \\
\hline \multicolumn{2}{|l|}{ Age } \\
\hline Mean (SD) & $53.0(13.6)$ \\
\hline Median & 54 \\
\hline Range & $(30-78)$ \\
\hline \multicolumn{2}{|l|}{ Gender } \\
\hline Male & $10(43.5 \%)$ \\
\hline Female & $13(56.5 \%)$ \\
\hline \multicolumn{2}{|l|}{ Race } \\
\hline White & $15(65.2 \%)$ \\
\hline Black/African American & $1(4.3 \%)$ \\
\hline Not reported & $7(30.4 \%)$ \\
\hline \multicolumn{2}{|c|}{ Cycles of Treatment (3 missing) } \\
\hline $0-1$ & $2(10 \%)$ \\
\hline $2-3$ & $10(50 \%)$ \\
\hline $4-5$ & $3(15 \%)$ \\
\hline $6+$ & $5(25 \%)$ \\
\hline \multicolumn{2}{|l|}{ Treatment Setting } \\
\hline Outpatient & $20(87 \%)$ \\
\hline Inpatient & $3(13 \%)$ \\
\hline \multicolumn{2}{|l|}{ ECOG Performance Status } \\
\hline 0 & $11(47.8 \%)$ \\
\hline 1 & $11(47.8 \%)$ \\
\hline 2 & $1(4.3 \%)$ \\
\hline \multicolumn{2}{|l|}{ Type of Disease } \\
\hline Unknown & $8(34.8 \%)$ \\
\hline Solid Tumor & $15(65.2 \%)$ \\
\hline \multicolumn{2}{|l|}{ Route of Treatment } \\
\hline Oral & $2(8.7 \%)$ \\
\hline IV bolus & $4(17.4 \%)$ \\
\hline IV continuous infusion & $5(21.7 \%)$ \\
\hline A combination of routes & $12(52.2 \%)$ \\
\hline
\end{tabular}

$\mathrm{N}$ : Number of patients

were 53 years old, equally male and female, and generally mobile (Table 2). Table 3 contains baseline QOL scores.

\section{Statistical analyses}

The small sample size is a limitation to the interpretability of statistical significance, thus any results are exploratory in nature.

The primary outcome, change from baseline, indicates patients' QOL decreased in all areas except for pain frequency, where there was a slight improvement (Table 3) (Figure 1). The mean change in overall QOL was slight $(-0.4,95 \%$ CI $[-0.92,0.05]$, effect size (ES) 0.36, $\mathrm{p}=0.08)$. Statistically significant mean changes were seen in physical WB $(-0.7$, 95\% CI [-1.46, -0.02], ES 0.41, p=0.04), emotional WB $(-0.6,95 \% \mathrm{CI}$ $[-1.17,-0.04]$, ES $0.46, \mathrm{p}=0.04)$ and $\operatorname{mood}(-0.9,95 \%$ CI $[-1.67,-0.07]$, ES $0.50, \mathrm{p}=0.03)$. Four patients experienced a clinically meaningful deficiency as defined by having an overall QOL decrease of at least 2 points.

No differences were seen between best treatment response (1 Partial Response, 13 Stable Disease, 8 Progressive Disease, 1 missing) and QOL scores. Correlations comparing QOL with AE grades were weak, the strongest being for emotional WB $(r=-0.41)$ and hopefulness $(\mathrm{r}=-0.35)$. The strongest correlation of change from baseline with maximum AE grade was with hopefulness $(\mathrm{r}=-0.56)$.

CPS indicated concordance in preferred and actual decision- 
Table 3. LASA QOL distribution.

\begin{tabular}{|c|c|c|c|c|}
\hline \multirow[b]{2}{*}{ QOL Domain } & \multirow{2}{*}{$\begin{array}{c}\text { Baseline (N=24) } \\
\text { Mean (SD) }\end{array}$} & \multicolumn{3}{|c|}{ Change from Baseline $(\mathrm{N}=\mathbf{2 3})$} \\
\hline & & Mean (SD) & Effect Size & T-test p-value \\
\hline 1. Overall QOL & $8.1(1.6)$ & $-0.4(1.1)$ & 0.36 & 0.08 \\
\hline 2. Mental WB & $9.0(0.9)$ & $-0.4(1.0)$ & 0.40 & 0.06 \\
\hline 3. Physical WB & $7.3(1.8)$ & $-0.7(1.7)$ & 0.41 & 0.04 \\
\hline 4. Emotional WB & $8.3(1.3)$ & $-0.6(1.3)$ & 0.46 & 0.04 \\
\hline 5. Level of Social Activity & $7.5(2.4)$ & $-0.1(1.1)$ & 0.09 & 0.71 \\
\hline 6. Spiritual WB & $8.8(1.4)$ & $-0.3(1.0)$ & 0.30 & 0.15 \\
\hline 7. Level of Hopelessness & $8.3(2.2)$ & $-0.5(1.2)$ & 0.42 & 0.06 \\
\hline 8. Frequency of Pain & $6.3(3.5)$ & $0.2(1.8)$ & 0.11 & 0.57 \\
\hline 9. Severity of Pain & $7.3(2.6)$ & $-0.4(1.6)$ & 0.25 & 0.25 \\
\hline 10. Level of Fatigue & $5.5(2.8)$ & $-0.5(2.2)$ & 0.23 & 0.31 \\
\hline 11. Level of Anxiety & $6.9(2.8)$ & $-0.3(2.2)$ & 0.14 & 0.45 \\
\hline 12. Overall Mood & $8.1(2.0)$ & $-0.9(1.8)$ & 0.50 & 0.03 \\
\hline 13. Level of Support & $9.8(0.5)$ & $-0.1(0.5)$ & 0.20 & 0.43 \\
\hline
\end{tabular}

N: Number of patients, SD: Standard deviation, QOL: Quality of life, WB: Well-being

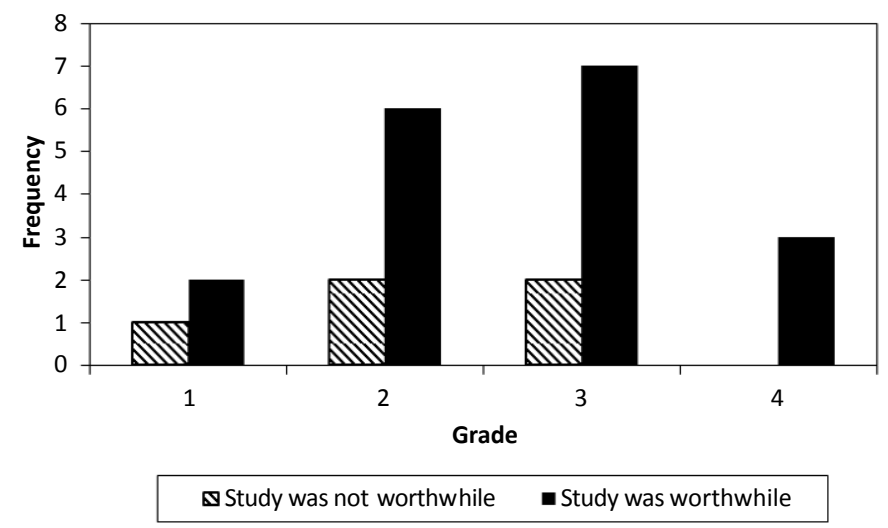

Patients were categorized as proclaiming the study was worthwhile or the study was not worthwhile. AE incidence and magnitude did not seem to be related to study worthiness.

Figure 1. Toxicity incidence and trial perception $(\mathrm{p}=0.77)$.

making roles. Nine patients (39\%) preferred and played an active role, twelve (52\%) a collaborative role and two (9\%) a passive role. Patients who preferred an active role had worse fatigue at the end of cycle 1 than those preferring a collaborative role ( -1.5 vs. 0.3 , ES $0.80, \mathrm{p}=0.04)$.

According to TS, treatment trial participation was worthwhile (mean 8.7, range 5.0-10.0), patients would do it again (mean 8.7, range 1.0-10.0), and they would recommend the trial to others (mean 9.2, range 5.0-10.0), but they did not feel QOL improved because of trial participation (mean 4.0, range 0.0-10.0). Correlation of LASA scores with TS yielded moderate associations, the largest being between decrease in pain frequency and worthwhileness of participating $(r=0.66)$. Change from baseline in any QOL score was not indicative of rating the parent trial as worthwhile. AE grade incidence was not a determinant in whether a patient rated the study worthwhile or not (Figure 1).

\section{Discussion}

Phase I trials can provide useful information for understanding how new drugs influence QOL, how adverse events influence specific domains of QOL, and how QOL deficits influence patients' treatment satisfaction. Our patients had decreases in all QOL areas except for pain frequency, which may be the result of increased clinician contact, thus improved pain amelioration. While overall QOL was non- significant and only 4 patients had a clinically meaningful decline in QOL, declines in QOL did exist, which may indicate areas for future interventions. Our results are consistent with Cohen et al. (2007) who found cancer treatment decreased QOL in physical, social, functional, and emotional areas [22].

Deficits in QOL were independent of AEs or tumor response in this study, confirming these endpoints do not act as surrogates. Patients felt it worthwhile to participate and would again, yet did not experience QOL improvement, indicating that QOL issues may also be independent of trial satisfaction. This may be reflective of the patient putting cure hopes above QOL needs, or QOL improvement was not expected in the first place. Patient trial satisfaction was high and this may be related to the perfect concordance in decision making roles.

Numerous studies support that increased communication between clinician and patient improves patient QOL. Meropol et al. (2008) indicated if the clinician knows the patient's preferences, communication is improved and distress is lessened, supporting the use of QOL assessments to facilitate communication [23]. Rummans et al. (2006) utilized a multi-disciplinary psychosocial intervention, which encouraged patients to communicate needs and results indicated a short-term improvement in overall QOL $(\mathrm{p}=0.047)$ and spirituality ( $\mathrm{p}=0.003$ ) [24]. Thus, patient QOL assessments may be used to facilitate a clinician-patient interaction to lessen all aspects of a patient's QOL concerns. In regards to future research, of interest would be to see if QOL, CPS concordance and trial satisfaction results hold true in a larger sample size and are maintained long-term, and our results are similar to Phase II or Phase III study patients.

The generalizability of this study is limited to the small sample size. Clinical staff reported an unwillingness to increase patient burden which may have introduced a selection bias. Patient refusal rate and refusal reasons were unrecorded. Further bias may stem from the heterogeneity of the treatments and distribution of toxicities experienced within the 12 studies included in this trial.

\section{Conclusions}

This work has shown that despite being satisfied with the trial experience, significant deficits occurred in various QOL subcomponents in the Phase I setting. The inclusion of QOL assessments in these trials may help identify areas of discussion for the clinician and patient to alleviate physical and psychosocial concerns of patients facing end of life care. 


\section{Authorship and contributorship}

Pamela J. Atherton, M.S.: study design, data collection, data analysis, writing

Daniel W. Szydlo, B.S.: data collection, data analysis, writing

Charles Erlichman, M.D.: patient enrollment, writing

Jeff A. Sloan, Ph.D.: study design, writing

\section{Funding information}

This study was conducted by the Mayo Clinic Cancer Center as protocol MC0115 and was supported by National Institutes of Health research grants CA 69912 and CA 15083.

\section{References}

1. Daugherty CK, Ratain MJ, Minami H, Banik DM, Vogelzang NJ, et al. (1998) Study of cohort-specific consent and patient control in phase I cancer trials. J Clin Oncol 16: 2305-2312. [Crossref]

2. Daugherty CK (2000) Informed consent, the cancer patient, and phase I clinical trials. Cancer Treat Res 102: 77-89. [Crossref]

3. Cheng JD, Hitt J, Koczwara B, Schulman KA, Burnett CB, et al. (2000) Impact of quality of life on patient expectations regarding phase I clinical trials. J Clin Oncol 18: 421-428. [Crossref]

4. Campbell S, Whyte F (1999) The quality of life of cancer patients participating in phase I clinical trials using SEIQoL-DW. J Adv Nurs 30: 335-343. [Crossref]

5. Gough IR, Furnival CM, Burnett W (1981) Patient attitudes to chemotherapy for advanced gastro-intestinal cancer. Clin Oncol 7: 5-11. [Crossref]

6. Cassileth BR, Lusk EJ, Miller DS, Hurwitz S (1982) Attitudes toward clinical trials among patients and the public. JAMA 248: 968-970. [Crossref]

7. Smith TL, Lee JJ, Kantarjian HM, Legha SS, Raber MN (1996) Design and results of phase I cancer clinical trials: three-year experience at M.D. Anderson Cancer Center. $J$ Clin Oncol 14: 287-295. [Crossref]

8. Estey E, Hoth D, Simon R, Marsoni S, Leyland-Jones B, et al. (1986) Therapeutic response in phase I trials of antineoplastic agents. Cancer Treat Rep 70: 1105-1115. [Crossref]

9. Decoster G, Stein G, Holdener EE (1990) Responses and toxic deaths in phase I clinical trials. Ann Oncol 1: 175-181. [Crossref]

10. Horstmann E, McCabe MS, Grochow L, Yamamoto S, Rubinstein L, et al. (2005) Risks and benefits of phase 1 oncology trials, 1991 through 2002. N Engl J Med 352: 895904. [Crossref]

11. Finlay E, Lu HL, Henderson HR, O'Dwyer PJ, Casarett DJ (2009) Do phase 1 patients have greater needs for palliative care compared with other cancer patients? Cancer 115 : 446-453. [Crossref]

12. Brady MJ, Cella D (1999) Assessing quality of life in palliative care. Cancer Treat Res 100: 203-216. [Crossref]

13. Glimelius B, Hoffman K, Haglund U, Nyrén O, Sjödén PO (1994) Initial or delayed chemotherapy with best supportive care in advanced gastric cancer. Ann Oncol 5: 189190. [Crossref]

14. Bretscher M, Rummans T, Sloan J, Kaur J, Bartlett A, et al. (1999) Quality of life in hospice patients. A pilot study. Psychosomatics 40: 309-313. [Crossref]

15. Sprangers MA, Schwartz CE (1999) Integrating response shift into health-related quality of life research: a theoretical model. Soc Sci Med 48: 1507-1515. [Crossref]

16. McCartney CF, Larson DB (1987) Quality of life in patients with gynecologic cancer. Cancer 60: 2129-2136. [Crossref]
17. Billings JA (2000) Recent advances: palliative care. BMJ 321: 555-558. [Crossref]

18. Degner LF, Sloan JA, Venkatesh P (1997) The Control Preferences Scale. Can J Nurs Res 29: 21-43. [Crossref]

19. Huschka MM, Mandrekar SJ, Schaefer PL, Jett JR, Sloan JA (2007) A pooled analysis of quality of life measures and adverse events data in north central cancer treatment group lung cancer clinical trials. Cancer 109: 787-795. [Crossref]

20. Sloan JA, Frost MH, Berzon R, Dueck A, Guyatt G, et al. (2006) The clinical significance of quality of life assessments in oncology: a summary for clinicians. Support Care Cancer 14: 988-998. [Crossref]

21. Parker RI, Hagan-Burke S (2007) Useful effect size interpretations for single case research. Behav Ther 38: 95-105. [Crossref]

22. Cohen MZ, Slomka J, Pentz RD, Flamm AL, Gold D, et al. (2007) Phase I participants' views of quality of life and trial participation burdens. Support Care Cancer 15: 885890. [Crossref]

23. Meropol NJ, Egleston BL, Buzaglo JS, Benson AB 3rd, Cegala DJ, et al. (2008) Cancer patient preferences for quality and length of life. Cancer 113: 3459-3466. [Crossref]

24. Rummans TA, Clark MM, Sloan JA, Frost MH, Bostwick JM, et al. (2006) Impacting quality of life for patients with advanced cancer with a structured multidisciplinary intervention: a randomized controlled trial. J Clin Oncol 24: 635-642. [Crossref]

25. Ma C, Mandrekar SJ, Alberts SR, Croghan GA, Jatoi A, et al. (2007) A phase I and pharmacologic study of sequences of the proteasome inhibitor, bortezomib (PS-341, Velcade), in combination with paclitaxel and carboplatin in patients with advanced malignancies. Cancer Chemother Pharmacol 59: 207-215. [Crossref]

26. Bible KC, Lensing JL, Nelson SA, Lee YK, Reid JM, et al. (2005) Phase 1 tria of flavopiridol combined with cisplatin or carboplatin in patients with advanced malignancies with the assessment of pharmacokinetic and pharmacodynamic end points. Clin Cancer Res 11: 5935-5941. [Crossref]

27. Hubbard J, Erlichman C, Toft DO, Qin R, Stensgard BA, et al. (2011) Phase I study of 17-allylamino-17 demethoxygeldanamycin, gemcitabine and/or cisplatin in patients with refractory solid tumors. Invest New Drugs 29: 473-480. [Crossref]

28. Dy GK, Mandrekar S, Peethambaram PP, Okuno SH, Croghan GC, et al. (2005) A phase I trial of celecoxib in combination with docetaxel and irinotecan in patients with advanced cancer. Cancer Chemother Pharmacol 56: 623-628. [Crossref]

29. Rao RD, Reid JM, Goetz MP, Furth AF, Mandrekar SJ, et al. (2004) Phase I trial of OSI-774 and CPT-11 in patients with advanced solid tumors (Abstract 3053). Program/ Proc Am Soc Clin Oncol 22.

30. Kumar S, Marks RS, Richardson R, Quevedo F, Croghan GA, et al. (2008) A phase study of the raf kinase/VEGF-R inhibitor sorafenib in combination with bortezomib in patients with advanced malignancy. (Abstract 2569) J Clin Oncol 26.

31. Mansfield AS, Fields AP, Jatoi A, Qi Y, Adjei AA, et al. (2013) Phase I dose escalation study of the $\mathrm{PKC}$ inhibitor aurothiomalate for advanced non-small-cell lung cancer, ovarian cancer, and pancreatic cancer. Anticancer Drugs 24: 1079-1083. [Crossref]

32. Goetz MP, Toft D, Reid J, Ames M, Stensgard B, et al. (2005) Phase I trial of 17-allylamino-17-demethoxygeldanamycin in patients with advanced cancer. $J$ Clin Oncol 23: 1078-1087. [Crossref]

33. Laheru D, Croghan G, Bukowski R, Rudek M, Messersmith W, et al. (2008) A phase I study of EKB-569 in combination with capecitabine in patients with advanced colorectal cancer. Clin Cancer Res 14: 5602-5609. [Crossref]

34. Dy GK, Bruzek LM, Croghan GA, Mandrekar S, Erlichman C, et al. (2005) A phase trial of the novel farnesyl protein transferase inhibitor, BMS-214662, in combination with paclitaxel and carboplatin in patients with advanced cancer. Clin Cancer Res 11: 1877-1883. [Crossref]

35. Adjei AA, Molina JR, Mandrekar SJ, Marks R, Reid JR, et al. (2007) Phase I trial of sorafenib in combination with gefitinib in patients with refractory or recurrent nonsmall cell lung cancer. Clin Cancer Res 13: 2684-2691. [Crossref]

36. Phase I trial of autologous dendritic cells loaded with Her500hGM (APC8024) for patients with advanced tumors that over-express HER-2/neu Trial conducted by Dendreon.

Copyright: (C2015 Atherton PJ. This is an open-access article distributed under the terms of the Creative Commons Attribution License, which permits unrestricted use, distribution, and reproduction in any medium, provided the original author and source are credited. 